\title{
DOCE VENENO DO ESCORPIÃO: PROBLEMATIZAÇÕES SOBRE A ECONOMIA DO SIMBÓLICO NOS DIÁRIOS DE RAQUEL PACHECO
}

\author{
SWEET SCORPIO POISON: PROBLEMATIZATIONS ON THE ECONOMY OF \\ THE SYMBOLIC IN THE DIARIES OF RAQUEL PACHECO \\ DOCE VENENO DEL ESCORPIÓN: PROBLEMATIZACIONES SOBRE LA \\ ECONOMIAA DEL SIMBÓLICO EN LOS DIARIOS DE RAQUEL PACHECO
}

Clóvis Carvalho Britto'

Resumo: o artigo analisa as configurações da economia simbólica no campo literário brasileiro a partir das estratégias em torno do livro $O$ doce veneno do escorpião, da escritora Raquel Pacheco. A obra suscita uma série de questionamentos em torno da escrita como expressão e simbolização, das relações entre pornografia, autoajuda e biografia, das instâncias de circulação e canais de visibilidade, provocando novos arranjos e posições nas relações de consumo do campo de produção simbólico. O trabalho parte dos referenciais de Pierre Bourdieu para investigar os discursos de algumas instâncias legitimadoras que se digladiam na batalha pelo (não) reconhecimento/distinção da obra de Raquel Pacheco no campo literário, com o intuito de esboçar as constelações de poderes que instituíram um novo filão no mercado editorial. A pesquisa também analisa, desse modo, os meios e as mediações empregados para a configuração da recém surgida literatura de programa.

Palavras-chave: Consumo. Comunicação. Campo literário.

Abstract: the paper analyzes the configuration of the symbolic economy in the Brazilian literary field from the strategies around the book $O$ doce veneno do escorpião, by the writer Raquel Pacheco. The work raises a series of questions about the writing as an

Professor da Faculdade de Ciência da Informação da Universidade de Brasília (UNB), Brasília, DF, Brasil. Doutor em Sociologia pela UNB. http://orcid.org/0000-0001-6267-544X. E-mail: clovisbritto@unb.br 
expression and symbolization, of the relations between pornography, self-help and biography, of the instances of circulation and channels of visibility, provoking new arrangements and positions in the consumption relations of the field of symbolic production. The paper is based on the references of Pierre Bourdieu to investigate the discourses of some legitimating instances that fought in the battle for (not) recognition / distinction of the work of Raquel Pacheco in the literary field, with the intention of sketching the constellations of powers that instituted a new in the publishing market. The research also analyzes, in this way, the means and the mediations used for the configuration of the newly emerged "program literature".

Keywords: Consumption. Communication. Literary field.

Resumen: el artículo analiza la configuración de la economía simbólica en el campo literario brasileño a partir de las estrategias en torno al libro $O$ doce veneno do escorpião, de la escritora Raquel Pacheco. El trabajo plantea una serie de preguntas sobre la escritura como expresión y simbolización, de las relaciones entre pornografía, autoayuda y biografía, de las instancias de circulación y canales de visibilidad, provocando nuevos arreglos y posiciones en las relaciones de consumo del campo de producción simbólica. El artículo se basa en las referencias de Pierre Bourdieu para investigar los discursos de algunos ejemplos legitimadores que lucharon en la batalla por (no) reconocimiento / distinción de la obra de Raquel Pacheco en el campo literario, con la intención de esbozar las constelaciones de poderes que instituyó una nueva en el mercado editorial. La investigación también analiza, de esta manera, los medios y las mediaciones utilizadas para la configuración de la recién publicada "literatura del programa".

Palabras clave: Consumo. Comunicación. Campo literario.

\section{Introdução}

A publicação de $O$ doce veneno do escorpião (2005), da escritora Raquel Pacheco², imprimiu uma série de repercussões e disputas que extrapolaram os limites que formatam o campo literário brasileiro. Publicado pela Editora Panda Books, o livro rotulado como uma não ficção permaneceu durante meses na lista dos mais vendidos no País, alcançando um sucesso editorial que superou o de inúmeras obras consagradas no cânone. $O$ doce veneno do escorpião, que em sua $20^{a}$. impressão atingiu a soma de 250 mil exemplares vendidos, quando o comum é que as editoras raramente alcancem vendagem de dez mil livros, teve seus direitos vendidos

\footnotetext{
2 Nascida em Sorocaba/SP, em 1984.
} 
para a Turquia, Coréia do Sul, Estados Unidos, Inglaterra, França, Canadá, Espanha, Holanda, Alemanha, Vietnã, Itália e Nova Zelândia. Turnês por estes e outros países e concorridas noites de autógrafos, lançamentos em capitais da América Latina onde uma versão em espanhol, El dulce veneno del escorpion, foi lançada pela Editora Planeta, que também fez a distribuição para os hispânicos nos Estados Unidos. De março a setembro de 2006, 32 mil exemplares foram vendidos para o público latino (cf. MATTOS, 2006). Em 2007, The Scorpion's Sweet Venom - The Diary of a Brazilian Call Girl foi publicado nos Estados Unidos pela Editora Bloomsbury, ano em que também foi publicado na França, pela Editora Michel Lafon, Le Doux Venin du Scorpion: Journal d'une Vendeuse de Plaisir.

Agenda cheia, coletivas com a imprensa internacional, palestras, participações em programas de televisão, sessões de autógrafos em São Paulo, Rio de Janeiro, Espírito Santo, Rio Grande do Sul, Pernambuco, Buenos Aires, Milão, Lisboa, Madrid, França e Holanda. Raquel se tornou um fenômeno editorial noticiado, inclusive, no The New York Times em matéria publicada em 27 de abril de 2006 e assinada por Larry Rohter, intitulada "Aquela que controla seu corpo pode irritar seus compatriotas" (ROHTER, 2006).

Seguindo o sucesso do primeiro livro, a autora também publicou pela Panda Books, com vendagens expressivas, O que aprendi com Bruna Surfistinha: lições de uma vida nada fácil (2006) e Na cama com Bruna Surfistinha: receitas de prazer e sedução (2007). Em 2006, o sucesso editorial foi o audiolivro, narrado pela autora e contendo algumas histórias inéditas. Raquel lançou histórias em quadrinhos eróticas na internet e teve sua vida representada no longa-metragem Bruna Surfistinha (Marcus Baldini, 2011) com argumento do cineasta Karim Ainouz e roteiro de Antônia Pellegrino. O filme foi dirigido por Marcus Baldini, a quem a autora concedeu entrevistas quinzenais: "os encontros são filmados e é possível que, além de dar subsídios para o roteiro do longa-metragem, o material seja utilizado posteriormente para um documentário sobre a garota" (MATTOS, 2007, p. 1).

Raquel Pacheco era praticamente desconhecida. Em uma conversa informal, poucos seriam capazes de associar seu nome a uma celebridade. Todavia, seu pseudônimo dispensa apresentações: ela é Bruna Surfistinha. Uma garota de programa que adquiriu fama instantânea ao relatar suas aventuras sexuais em um blog que já atingiu cerca de quinze mil acessos diariamente. O sucesso de sua história de vida descortinada na internet contribuiu para que Raquel publicasse $O$ doce veneno do escorpião (escrito pelo jornalista Jorge Tarquini, a partir de depoimentos da autora).

Editado em formato de bolso ( $13 X 18 \mathrm{~cm}$ ), é um livro sugestivo que, não sem motivos, encontrou lugar cativo nas estantes dos mais vendidos em livrarias de 
norte a sul do País. A antítese do título que combina leveza e morte, dialoga com a metáfora/metonímia do escorpião que, além de na astrologia acenar para a sexualidade, é o signo regente da escritora e sua marca corporal, visto que Raquel o tatuou nas costas, fato divulgado na foto de orelha do livro. Se as figuras de linguagem sublinham um título poético, o subtítulo - diário de uma garota de programa - fornece pistas a respeito do conteúdo da obra/best-seller. O folhear das primeiras páginas remete o leitor ao eixo condutor do livro: "Transas enlouquecidas, surubas, muitos homens (e mulheres) diferentes por dia, noites quase sem fim. (...) Trabalho que escolhi por não ter outra escolha quando... Bem, é uma longa história. A minha, pessoal, e a da Bruna. Sim, somos duas. Com duas histórias diferentes numa mesma garota: eu" (SURFISTINHA, 2005, p. 10-11).

Seus livros revelam o percurso de uma prostituta de classe média que modificou a trajetória em função de um "verdadeiro amor", no caso, de um cliente que se apaixonou por ela e abandonou mulher e filhos para seguir o romance e retirar a garota da prostituição. Fato que contribuiu para mais uma explosão discursiva em torno de Raquel, que se tornou personagem do livro escrito pela mulher traída, Samantha Moraes (2006), no qual revela sua versão da história: Depois do Escorpião: uma história de amor, sexo e traição.

Reconhecendo que esse projeto criador era, até então, incomum no campo literário brasileiro, acreditamos que as análises da trajetória da autora, de suas estratégias, dos obstáculos e críticas encontradas, além de suas escolhas temáticas e comunicacionais, além do estudo das mediações e das reverberações que seus livros provocaram em diferentes campos de produção de bens simbólicos resultando em fama instantânea e lucratividade, possibilitarão uma melhor compreensão das interconexões entre cultura e economia. Sabedores de que os processos inseridos na dinâmica da economia dos afetos suscitam uma série de reflexões no que concerne às relações entre mercadoria e símbolo, matéria e espírito, indústria e cultura, dentre outros binômios, nosso propósito consiste em iluminar alguns desses aspectos tendo como exemplo os livros da escritora Raquel Pacheco sob a tônica das transformações da esfera cultural guiadas pelas imposições do mercado de bens simbólicos.

Esses processos demonstram uma diluição das fronteiras entre economia, cultura e afeto e provocam efeitos sobre a lógica dos usos e percepções. A leitura dos diários de Surfistinha suscita uma série de questionamentos em torno da escrita como expressão e simbolização, das relações entre pornografia, autoajuda e biografia, das instâncias de circulação e canais de visibilidade, das mediações, 
enfim, espraiam as veredas entre expressão e produção cultural, provocando novos arranjos e posições nos entrelaçamentos entre profissionalismo e prazer.

De acordo com Edson Farias (2005), a ideia da economia de símbolos encaminha para a percepção da instituição de uma educação dos sentidos agindo sobre as percepções e estimas, dizendo respeito à maneira que na sociedade de consumidores o entretenimento se define como um mecanismo de consagração e instância de legitimação das práticas culturais: "a economia simbólica se define pela característica mútua que passa a articular ócio e negócio" (FARIAS, 2005, p. 667).

Nossa opção analítica se detém em inventariar algumas das estratégias utilizadas pela escritora e por mediadores para a produção da crença na personagem Bruna Surfistinha. Torna-se imperioso indagarmos os espaços de possíveis que transformaram os escritos de seu blog em um best-seller internacional, os contornos que propiciaram a legitimidade de sua marca, sua recepção e o papel exercido por alguns meios e mediadores nesse processo que imbrica capitais simbólico e econômico. Daí seguir o pressuposto de Débora Leitão e Rosana Machado, quando consideram que os bens, em si, são nulos:

[...]só agregam valor e autenticidade dentro de um determinado contexto social. Nesse sentido, tal valor de um objeto - longe de estar associado puramente às suas propriedades materiais intrínsecas - é um ato simbólico e social que passa pelos discursos legitimadores de determinados grupos e classes (LEITÃO; MACHADO, 2006, p. 23).

Analisaremos, assim, os discursos de algumas instâncias legitimadoras que se digladiam na batalha pelo (não) reconhecimento/distinção da obra de Raquel Pacheco no campo literário, com o intuito de esboçarmos as constelações de poderes que essa obra suscita aos olhos da crítica e dos leitores e os prováveis motivos pelos quais é preferida dentre inúmeras outras que possuem, inclusive, temáticas e recursos semelhantes.

\section{Literatura de "programa"?}

Se nos guiarmos pela máxima de que uma obra ainda está viva quando tem leitores, podemos considerar que a de Raquel Pacheco ainda viverá por algum tempo. Mas quais os critérios que definem ser uma obra boa ou má literatura? A quantidade de livros vendidos? O número de traduções? A quantidade de estudos críticos? O reconhecimento pelos pares? A questão se complexifica se atentarmos para o fato de que a obra é um fato único que renasce sempre diverso a 
cada leitura. Como explicar, por exemplo, por que a crítica literária se indigna ao reconhecer que $O$ Alquimista, de Paulo Coelho tenha atingido um número bem maior de leitores do que Grande Sertão: Veredas, de João Guimarães Rosa? Ambos não foram reconhecidos pela Academia Brasileira de Letras? Por que apenas o segundo constitui uma unanimidade crítica? O que produz a diferença entre as obras? A questão é que os critérios para a canonização e para a aceitação no mercado são, em sua maioria, extraliterários.

O contexto mudou, os protocolos de leitura mudaram. Como bem reconhece Leyla Perrone-Moisés (1999, p 176):

Os novos escritores não estão nem um pouco interessados em ingressar no cânone; interessa-lhes ter seus livros rapidamente publicados, traduzidos em línguas hegemônicas, adaptados para o cinema e para a televisão; para conseguir esses objetivos, não é necessário 'um longo assentimento', basta figurar na lista dos mais vendidos.

Talvez a resposta para algumas questões seja a conclusão acenada pela analista literária:

A difusão dos livros passa, atualmente, menos pelos críticos e professores universitários do que pelos agentes literários, e pelas várias formas de publicidade. Quanto aos leitores de literatura, em geral esses se interessam pouco por discussões acadêmicas (PERRONEMOISÉS, 1999, p. 176).

Observamos que, para a especialista, a difusão dos livros passa mais pelos agentes e pelas formas de publicidade, com o intuito de serem consumidos rapidamente. Fatos que nos remetem às lições de Zygmunt Bauman (2007) quando analisa a celebridade, personagem característico dos tempos líquido-modernos. $\mathrm{Na}$ verdade, o fator decisivo para a legitimidade, seria a notoriedade, a abundância de suas imagens e a frequência com que seus nomes são citados na mídia e nas conversas cotidianas: "diferentemente da fama, a notoriedade é tão episódica quando a própria vida num ambiente líquido-moderno" (BAUMAN, 2007, p. 68), concluindo que a ação das celebridades, "cada qual aparecendo do nada só para cair rapidamente no esquecimento, é eminentemente adequada à marcante sucessão de episódios das existências fatiadas" (BAUMAN, 2007, p. 68). E os próprios autores têm consciência disso. No caso de Raquel Pacheco, ela afirma em seus livros: "sei que tudo que aconteceu na minha vida, a fama sei, sei, passageira" (SURFISTINHA, 
2005, p. 129) ou "muita gente pode me acusar de estar apenas aproveitando meus '15 minutos de fama' ao lançar este livro" (PACHECO, 2006, p. 9).

Surge, nesse momento, outra pergunta: de que maneira as veredas entre cultura do livro e realidade midiática confluem na inovação da literatura? Observamos uma tendência da literatura se aproximar de novas possibilidades expressivas. Todavia, devemos reconhecer que ainda que o livro "sumarie o mundo da cultura, ao qual se articula, independentemente do que possa conter, ele jamais perde a sua dimensão de produto industrial que circula graças ao comércio que suscitou e que depende dele", concluindo que ele se insere "de forma integral nas diferentes economias em vigência no mundo moderno" (LAJOLO; ZILBERMAN, 2001, p. 159).

O preço de um livro ultrapassa a simples adição dos elementos do custo de produção e, por isso, o editor, o propagandista e outros mediadores, têm assumido um papel crucial. É importante estar sempre atento às tendências do mercado, buscar inovações, atender aos anseios do público consumidor, o que para Bourdieu (1998) seria instituir a diferença legítima no espaço dos possíveis. O entendimento remete a um sistema objetivo com mecanismos e conceitos específicos, formador da crença que suporta relações. É essa crença que sustenta o campo, "do jogo de linguagens que nele se joga, das coisas materiais e simbólicas em jogo que nele se geram" realizando um encontro entre "uma pulsão expressiva e um espaço dos possíveis expressivos, que faz com que a obra, ao realizar as duas histórias de que ela é produto, as supere" (BORDIEU, 1998, p. 69-70). As lutas travadas em busca da hegemonia, caracterizadas pelo reconhecimento e pela manutenção de bens simbólicos como a distinção, o prestígio, o poder de ditar as regras, de consagração e legitimidade, constituem o motor do campo.

No campo literário, a cada sobreposição de gêneros, construção de estilos, adoção de temáticas e comportamentos e surgimento de novos escritores, a luta se renova: os estreantes querem ser reconhecidos e os consagrados buscam manter as prerrogativas que contribuíram para sua aceitação e conservação contra as investidas dos recém-chegados. Após a inserção torna-se necessário lutar pela permanência e pela distinção, superando as provas definidas pelos anteriormente legitimados na busca pelo reconhecimento das produções.

Nesse aspecto, fato importante a ser considerado é a edição de diários de ex-prostitutas e o livro de Raquel Pacheco é um dos precursores desse filão no Brasil. Seguindo o exemplo, vários livros começaram a ser editados, como $A$ agenda de Virgínia: uma prostituta de luxo revela sua vida dupla, da ex-prostituta espanhola Alejandra Duque (2006), e O diário de Marise: a vida real de uma garota de programa, da ex-prostituta Vanessa de Oliveira (2006), de Balneário 
Camboriú-SC. Percebe-se que o fenômeno não é exclusivo do Brasil, mas no caso de Raquel Pacheco/Bruna Surfistinha, a diferença é que os leitores podiam acompanhar e opinar sobre cada história disponibilizada no blog, e a internet constituiu um meio não só de divulgação, mas, digamos, de um teste prévio da aceitação do produto, mesmo que inicialmente não fosse intenção publicar um livro: "quando eu finalmente encontrei no blog uma maneira de me expressar, de contar para as pessoas um pouco mais de mim, descobri que o que eu queria, de verdade, era ser reconhecida. Não que eu quisesse ser uma pop star. De alguma maneira, isso me fazia diferente" (PACHECO, 2006, p. 53).

O sucesso imediato da chamada literatura de programa, provocou uma série de reações: "muita gente, mesmo sem ter lido o livro $O$ doce veneno do escorpião, partiu para o ataque, dizendo que eu estava fazendo apologia da prostituição e das drogas, incentivando, assim, meninas 'desmioladas', a seguir o meu exemplo. [...] Eu senti que minha experiência poderia ajudar outras pessoas de alguma forma" (PACHECO, 2006, p. 9). Aspecto também ressaltado era o fato de que os livros não transgrediam, eram moralistas e que contribuíam para reforçar os lugares sociais estabelecidos. Segundo a pesquisadora Eliane Robert Moraes:

O livro de Bruna Surfistinha e seus similares não são eróticos, porque a literatura erótica mobiliza a fantasia, o que não ocorre com esses diários das ex-prostitutas. Esses livros são moralistas, não têm nada de transgressão, reafirmam os lugares sociais. O fato de todas deixarem a prostituição segue o modelo da auto-ajuda, de Paulo Coelho, do herói que passa pelas provas e que no final é recompensado. [...] O misticismo de Paulo Coelho e o erotismo de Surfistinha são 'light', perdem o que é mais importante: a capacidade de perturbar lugares sociais, de transcender. Ao contrário, são normalizadores. [...] O sucesso de vendas dos diários de ex-garotas de programa, está ligado à demanda de voyeurismo da sociedade. E, no fundo, esses livros atendem a uma sociedade que deve estar com sua sexualidade muito reprimida, não obstante o sexo e o erotismo presentes no horário nobre da televisão (MORAES entrevistada por CARDELLO; MATTOS, 2006, p. 1).

Opinião também apresentada por Sérgio Telles (2007). Para ele, a história romântica, recheada de conselhos aos leitores e apimentada com o que considera ser uma pornografia light, ao demonstrar os erros de uma prostituta redimida pelo amor, reafirma a visão convencional e moralista sobre a prostituição, acomodada aos estereótipos do imaginário coletivo, fato que, provavelmente, explicaria o seu 
sucesso comercial. Todavia, reconhece que ela quebra um estereótipo: "sendo ela moça de classe média, sua realidade não está tão distante da de seus leitores, o que não ocorre com os relatos de prostituição feitos por aquelas que ali chegam por uma pressão direta da miséria socioeconômica" (TELLES, 2007, p. 2).

A discussão acenada pelos críticos não é descabida. Ao contrário, os debates sobre erotismo e pornografia vêm de longa data. Enquanto a pornografia é considerada como aquilo que torna o sexo como produto de consumo, o erotismo tende ao sublime e ao sugestivo. Para Jorge Leite Jr. (2006), essas diferenças e classificações consistem em uma luta simbólica pela legitimidade das representações e práticas sexuais. Relembrando Bourdieu (1998), afirma que a luta por classificação e separação entre erotismo e pornografia consiste em uma batalha por legitimação de um poder estabelecido através da distinção social.

O que importa reconhecer é que, independentemente desses enquadramentos, as representações eróticas ou pornográficas são obscenas, se encontram fora de cena. Foucault (2007) reconhece que a produção dos discursos é ao mesmo tempo organizada, controlada e redistribuída por procedimentos que conjugam poderes e perigos. Em nossa sociedade, um desses procedimentos seria a exclusão, manifesta através de uma série de interdições.

Desse modo, existiriam procedimentos de controle dos discursos que determinam condições e regras de funcionamento, não permitindo que eles sejam acessíveis a todos. Para Foucault (2006), ninguém integra a ordem do discurso se não for qualificado para fazê-lo e nem todas as suas regiões são penetráveis, sendo, algumas, altamente proibidas como a da sexualidade: "o discurso sobre o sexo, já há três séculos, tem-se multiplicado em vez de rarefeito; e que, se trouxe consigo interdições e proibições, ele garantiu mais fundamentalmente a solidificação e a implantação de todo um despropósito sexual" (FOUCAULT, 2006, p. 61). Todavia, "tudo isso parece ter desempenhado, essencialmente, um papel de proibição. De tanto falar nele e descobri-lo reduzido, classificado e especificado, justamente lá onde o inseriram procurar-se-ia, no fundo, mascarar o sexo" (FOUCAULT, 2006, p. 61).

A questão complica quando se relacionam texto pornográfico e autoria feminina. Apesar de não ser a tônica deste trabalho, convém salientarmos que se falar de sexo em nossa sociedade, por si só, é uma transgressão, as mulheres que escrevem à luz dessa temática provocam, no mínimo, constrangimentos. Se antes elas não podiam conviver com o universo da escrita; depois, como autoras, deveriam seguir determinados protocolos, chegando, inclusive, a escrever e assinar com pseudônimos masculinos e adotar certos estilos e temas; agora, 
ao escrever sobre sexo, as mulheres promovem um deslocamento, passam da condição de objeto, para a de enunciadora do desejo.

Cumpre, desse modo, questionar quem é o verdadeiro produtor do valor de uma obra? O que faz a reputação, a crença? E, no caso dos livros de Raquel Pacheco, como surgiu a crença na personagem/autora Bruna Surfistinha? Quais as estratégias mobilizadas e de que modo os clientes/leitores contribuem para a construção de seu valor?

\section{Dos meios às mediações}

De acordo com Bourdieu (2002), a oposição entre o comercial e o não comercial é o princípio gerador da maior parte dos posicionamentos que, no campo artístico, pretendem instaurar a fronteira entre o que é e o que não é arte. Essa divisão se estabelece entre "a produção restrita e a grande produção (o comercial), ou seja, entre o primado atribuído à produção e ao campo dos produtores ou, até mesmo, ao subcampo dos produtores para produtores, e o primado atribuído à difusão, ao público, à venda, ao sucesso avaliado pela tiragem" (BOURDIEU, 2002, p. 30-31). O autor cita as oposições entre o que seria o sucesso duradouro dos clássicos e o sucesso imediato e temporário dos best-sellers e afirma que as características do empreendimento comercial e do empreendimento cultural, estão indissociáveis. Bourdieu demonstra que o que faz as reputações não são as influências "de fulano ou sicrano, esta ou aquela instituição, revista, publicação semanal, academia, cenáculo, marchand, editor" (2002, p. 25), concluindo que a reputação é criada pelo "campo de produção como sistema de relações objetivas entre esses agentes ou instituições e espaços das lutas pelo monopólio do poder de consagração" (BOURDIEU, 2002, p. 25). Nesse sentido, torna-se importante investigarmos algumas das estratégias empreendidas por Raquel Pacheco e seus mediadores, que provocaram o itinerário que a transformou a ex-garota de programa em escritora sucesso de vendas.

Num primeiro momento, verifiquemos as especificidades da trajetória social da autora e de seu projeto criador que certamente contribuíram para a instituição da crença em seu nome/personagem. Conforme já destacamos, o fato de a autora ser uma jovem de classe média, detentora de um alto capital cultural, por si só firma um lugar de fala. Não é uma garota que se prostituía por dificuldades financeiras e que relata suas aventuras sexuais para um público que possui dinheiro para comprá-las e tempo para lê-las. Ao contrário, Raquel não vive uma realidade muito distante da de seu público leitor, fator que a torna íntima dele e isso faz muita diferença. 
Nos livros, confessa que o motivo que a levou para a prostituição foi um trauma decorrente da descoberta de sua adoção: "sua ida para a prostituição, decorreria de graves problemas identitários, já sinalizados por sintomas anteriores, como a obesidade, a cleptomania, as ideias de suicídio e o uso de drogas", destacando que "talvez tenha usado da capacidade de escrever para organizar e simbolizar o caos psíquico e com isso escapar da loucura" (TELLES, 2007, p. 3).

Provavelmente existe uma identificação de grande parcela dos leitores com os conflitos familiares e pessoais narrados pela autora. Do mesmo modo, poderia existir aproximação com a linguagem e com o modo com que ela discorre sobre determinados temas, além da curiosidade sobre os bastidores da profissão e os motivos que a teriam levado a escolher o ofício. Não sem motivos, quem escreve a obra não é uma escritora prostituta, mas, sim, uma ex-garota de programa escritora. Daí alguns críticos ressaltarem a estratégia da instituição de uma história romântica em que ao final a mocinha se converte em escritora e conselheira sentimental. Todavia, seus livros não são apenas um memorial laboral, são ritos de passagem, mecanismos utilizados para "matar" o lado prostituta. Para Joel Birman "é como se fosse um enterro. A própria escrita deve servir como ritual de purificação. Tem peso simbólico de retomada de sua 'verdadeira' condição" (entrevistado por CARIELLO; MATTOS, 2006, p. 1).

Por isso, a autora faz a opção por se dividir em duas personalidades ou, o que literariamente poderíamos dizer, por construir duas máscaras líricas. Enquanto Raquel é a personagem que remete às trajetórias anterior e posterior à prostituição, Bruna Surfistinha é a que realizou o papel de prostituta, e que não existe mais, a não ser na ficção. Raquel une as pontas do passado e do presente, já Bruna vive no passado: "quando este livro estiver lançado eu não estarei mais fazendo programas, vou me aposentar" (SURFISTINHA, 2005, p. 134). A inovação foi a descrição e divulgação das suas artimanhas sexuais na internet, fato que Ihe proporcionou visibilidade e a tornou mais próxima dos leitores, dando-lhe credibilidade. Em 2004, Raquel decidiu escrever seu diário disponibilizando-o em um site particular no qual mantinha seu blog e inseria fotos: "foi com este site que comecei a ter sucesso. Com as fotos conquistei a credibilidade das pessoas que não acreditavam que aquele blog era de uma garota de programa de verdade" (SURFISTINHA, 2005, p. 89). E o que era inicialmente uma prática do ócio, se transformou rapidamente em negócio: “Meu blog adquiriu repercussão. [...] Algo tão espontâneo acontecia que o próprio lbest me chamou para dizer que o meu blog estava em segundo lugar no top link" (SURFISTINHA, 2005, p. 89). Estratégia eficaz na produção da crença na grife Surfistinha. Devido aos milhares 
de acessos diários, ela foi convidada pela Editora Panda Books a publicar o seu diário-biografia e, assim, surgiu a ideia de escrever $O$ doce veneno do escorpião. Utilizando o conteúdo divulgado no blog e depoimentos de Raquel, o primeiro livro foi escrito com o auxílio ${ }^{3}$ de Jorge Tarquini, jornalista e professor de crítica de mídia e marketing:

Na verdade, a Raquel (Bruna) havia dito em seu blog que estava querendo escrever um livro contando sua história. Eu não conhecia o blog. O Marcelo Duarte, editor da Panda Books, que é meu amigo, leu o blog, me contou por alto do que se tratava e me disse para procurá-la e convencê-la a fazer o livro conosco - e que eu seria o escritor. Nunca havia pensado em escrever nada nessa linha e foi uma grande surpresa. [...] Nem de longe esse era um trabalho comum. Por isso, já começamos de um modo diferente: combinamos que cada sessão de entrevistas duraria o tempo exato de um programa, uma hora, e seria tudo feito no seu flat, onde ela atendia seus clientes. Para não ferir o trato, eu levaria uma fita cassete de 60 minutos para cada encontro. Foram 12 fitas, gravadas em pouco mais de um mês. [...] Esse é meu trabalho. Sou um jornalista. Claro que há sempre o receio de como o trabalho vai ser recebido. Tive alguns comentários maldosos, gente que me escreveu dizendo que eu era um "prostituto" da minha profissão. Por outro lado, tive a honra de receber boas críticas e elogios nominais do Giron e do Elio Gaspari, por exemplo. Como eu também sou professor em uma universidade confessional, a Metodista, no curso de Jornalismo, talvez pudesse ter algum questionamento. Mas houve maturidade por parte deles para entender que, como um profissional do mercado que dedica uma parte de seu tempo para lecionar, não poderia haver interferência nesse nível. E os alunos curtiram muito. Ganhei um glamour inesperado. [...] Para a minha carreira abriu-se mais uma porta. Estou com outros dois projetos de livros, para os quais fui convidado. E espero que outros venham. Inclusive um meu, sem falar da vida de terceiros. Talvez uma ficção, um romance. Planos meus. (RUBINSTEINN, 2006).

Surge, então, uma série de estratégias visando abrir portas. O sujeito da obra de arte não é um artista singular, nem um grupo social, mas o campo da produção

\footnotetext{
3 Conforme sinaliza Sérgio Telles (2007), apesar da colaboração do jornalista nos textos do primeiro livro [lembrando que os demais livros foram escritos exclusivamente por Raquel] "a autoria dos mesmos não pode ser colocada em questão ou atribuída a um ghost writer. Não podemos esquecer que foi dela a ideia de criar um blog e nele escrever regularmente suas experiências, acobertada pelo 'personagem' Bruna Surfistinha" (2007, p. 3).
} 
artística em seu conjunto de agentes que teriam "uma ligação com a arte, que se interessam pela arte, que vivem da arte e para a arte, produtores de obras consideradas como artísticas (grandes ou pequenas, célebres, isto é, celebradas ou desconhecidas)" (BOURDIEU, 1983, p. 172) como críticos, intermediadores, prefaciadores etc. No caso em análise, observamos que todos os envolvidos com o projeto, especialmente a escritora, o jornalista e a Editora Panda Books, se iluminaram com a energia social acumulada no "espaço de possíveis" e, ao mesmo tempo, se legitimam e são legitimados mutuamente.

Devemos considerar também o crescente interesse por biografias no campo literário, transformando a vida como entretenimento/espetáculo. Segundo Marília Cardoso (2002), na condição pós-moderna há um descrédito pelas grandes narrativas, a biografia perdeu seu lugar no plano da considerada alta cultura e se transformou em best-seller no circuito mercadológico, especialmente pela banalização dos processos de ascensão e queda de artistas e personalidades difundida pelos meios de comunicação de massa. Já o biógrafo se coloca no lugar de herdeiro do biografado e, artista e obra acabam se confundindo, se transformando em imagens lucrativas. A biografia se transforma em uma espécie de ritual de consagração pública, em um subgênero narrativo que vive nos interstícios entre a literatura e a história, tendendo, algumas vezes, para o jornalismo.

Para Micael Herschmann e Carlos Pereira uma possível explicação pelo crescente interesse por biografias é porque elas possibilitam

ordenar a realidade, cristalizando temporariamente identidades, projetos de vida, seja para o sujeito biografado, seja para quem consome este tipo de produto. Neste quadro é possível também constatar a relevância, cada vez maior, que é dada a memória [...] 'grande obsessão' (HERSCHMANN; PEREIRA, 2002, p. 143).

Seria uma tentativa de compensar a experiência contemporânea de vida fragmentada e o material biográfico ficcional e não ficcional, de certo modo, "alimenta e recria o contexto de cidade pequena, bairro, formando comunidades de fãs e consumidores" (HERSCHMANN; PEREIRA, 2002, p. 148). Desse modo, a demanda por biografias, representa um pouco de voyeurismo, o interesse pela vida enquanto entretenimento, e as novas tecnologias contribuiriam para a que a vida seja transformada em um espetáculo grandioso e ininterrupto.

No caso do livro em estudo, o que ocorre com as biografias de um modo geral, é que não só Bruna Surfistinha é um personagem criado por Raquel Pacheco, mas 
a própria Raquel se transforma em um personagem, uma outra ficção, visto que a imagem construída na obra "atende mais ao desejo de mostrar uma bela figura para a posteridade do que ser fiel aos fatos" (TELLES, 2007, p. 3). Portanto, a edição de $O$ doce veneno do escorpião sob a forma de um diário e sua subdivisão em três partes, sendo que a primeira intercambia a vida de Raquel e de Bruna, a segunda a descrição das aventuras sexuais, e a última, em páginas negras e lacradas, as histórias consideradas proibidas, foi intencional e segue a tendência dos grandes sucessos editoriais do gênero. Sérgio Telles (2007), atenta para o fato de que os livros de Raquel Pacheco atendem a uma disposição editorial específica, possuem um corpo extenso de páginas brancas e um outro menor, de páginas pretas lacradas,

onde supostamente estaria o material mais censurado. É uma divisão arbitrária, que atenderia mais a um marketing visando estimular a curiosidade acerca do material 'proibido', pois não há diferença notável no teor dos textos assim discriminados (TELLES, 2007, p. 2).

O texto, além de biográfico e não ficcional, é apresentado como autoajuda, classificação informada nos livros e no material de divulgação da editora. Ora, se Raquel aprendeu com Bruna, como explicitado no título do segundo livro, seus leitores também poderiam aprender lições e superar suas dificuldades: "Bruna também dá pequenas lições para uma mulher de como conquistar o homem, e jamais perdê-lo para uma garota de programa" (TELLES, 2007, p. 2). Ressalta: "Muitas mulheres me enviam e-mails, perguntando o que fazer para dar prazer ao homem na cama, como conquistar o próprio prazer, como se livrar dos medos de fazer sexo" (Rachel Pacheco entrevistada por TELLES, 2007, p. 2). E revela: "Os homens, por sua vez, querem saber como lidar com mulheres que não têm disposição para o sexo, que não conseguem gozar... Enfim, ainda restam dúvidas sobre sexo que sei que posso ajudar a esclarecer" (IDEM, p. 2).

Mas quem é o público que consome os livros de Raquel Pacheco? Ou, de um modo geral, quem é o público leitor no Brasil? No caso do campo literário brasileiro essa é ainda uma questão com poucas respostas. Gilberto Mendonça Teles (2002), em estudo sobre a produção e recepção de livros no Brasil, reconhece a necessidade de pesquisas mais aprofundadas e aponta para o fato de que ainda quase nada foi feito em relação a um levantamento das condições materiais e institucionais da produção e da recepção da mensagem, nem das técnicas de reprodução, conservação e de transmissão dos discursos, oral e escrito. Ressalta 
que desconhecemos o nosso mercado do livro, edição, número de edições, difusão e distribuição e lança algumas perguntas por enquanto com poucas respostas: Quem lê o escritor brasileiro? Que tipo de público o lê? Qual o gosto do leitor? Qual a dimensão e a condição social do leitor?

A pesquisa Retratos da Leitura no Brasil (AMORIM, 2008), coordenada pelo Instituto Pró-Livro e executada pelo IBOPE, se não escancara as respostas, deixa a porta, no mínimo, entreaberta. Iluminando possíveis caminhos a respeito da leitura no Brasil entre os anos 2000 e 2007, analisou a percepção da leitura no imaginário coletivo, o perfil do leitor e do não leitor de livros, as preferências, canais, formas e barreiras à leitura. A amostra definida representa todo o universo da população brasileira a partir de cinco anos de idade (172.731.959 pessoas), e possui 1,4 \% de margem de erro e $95 \%$ de intervalo de confiança. Da infinidade de dados explicitados, selecionaremos os que, acreditamos, esclarecem ou vão ao encontro de algumas das questões suscitadas neste artigo. Consultados sobre o que os brasileiros gostam de fazer no tempo livre, $35 \%$ dos entrevistados (6o milhões de pessoas) declararam a leitura, todavia, a maioria das respostas assinala como prioridades assistir televisão, ouvir música, descansar e ouvir rádio. Questionados sobre os gêneros mais lidos, 27 \% dos entrevistados afirmaram se interessar por biografias e livros de autoajuda. A pesquisa também revela que a grande motivação para a leitura é o prazer e que os fatores que mais influenciam são o tema e o título - para quem estudou mais ou ganha mais -, e o autor - entre a maioria dos que possuem escolaridade e renda mais baixa. Mas, independentemente da classe social e escolaridade, para considerável parcela da população os principais fatores que influenciam na escolha de um livro, além da trilogia tema/título/autor, são as dicas de outras pessoas, a capa e a publicidade. Evidencia-se, desse modo, a importância das mediações, atualmente reconfiguradas, gerando novas formas de interpelação dos sujeitos e de representação.

No caso em análise, vimos que os livros de Raquel não são apenas um meio, mas também um modo de mediação, de mistura de linguagens, eles aproximam os discursos da ficção e não ficção, biografia, autoajuda e sexualidade, e seu conteúdo pode ser lido tanto nos livros, quantos na internet. Podemos, em certa medida, nos guiar pelas análises de Jesús Martin-Barbero (2008) quando estudou a literatura de cordel. Segundo informa, ela seria uma outra literatura, que se move entre a vulgarização do que vem de cima e a sua função de resistência, de válvula de escape a uma repressão que explode na forma de sensacionalismo e sarcasmo. Desse modo, ao invés de inovar, estereotipa linguagem e argumentos 
em função das imposições da comercialização e adaptação do gosto a alguns formatos, mas também dos modos de repetição e narração.

Martin-Barbero (2008) identifica o surgimento de uma mediação institucional com o mercado que se coloca entre o escritor e o texto cujo exemplo maior seria o folhetim. No folhetim, avalia que muitas vezes o autor ditava para um ajudante e o ditado revela o que este gênero possui de oral, uma proximidade com uma literatura na qual o autor fala mais do que escreve e o leitor escuta mais do que lê. Efeito reforçado pelas fragmentações "que vão desde o tamanho da frase e do parágrafo até a divisão do episódio em partes, capítulos e subcapítulos" (2008, p. 187) e pelos chamados efeitos de sedução, em sua organização por episódios e sua estrutura aberta: "a estrutura aberta, o fato de escrever dia após dia conforme um plano que, entretanto, é flexível diante da reação dos leitores também se inscreve na confusão da narrativa com a vida, permitida pela duração" (MARTIN-BARBERO, 2008, p. 187).

Essas estratégias do folhetim remetem, de certo modo, a algumas das táticas utilizadas na elaboração de $O$ doce veneno do escorpião e que também poderiam ser uma explicação para o seu sucesso de público. Assim como ocorria com alguns autores de folhetim, Raquel narrou sua história a um ajudante, e seu livro está marcado por uma necessidade de contar $a$, por isso a ideia de um diário. O próprio fato de escrever um diário e publicá-lo na internet, possibilita que os leitores acompanhem cotidianamente as histórias, gerando a sensação de participação e, provavelmente, por isso, que mesmo após a publicação dos livros, Raquel/Bruna ainda continue atualizando seu diário virtual e mantendo uma legião de seguidores ávidos pelas informações disponíveis em seu site nos links: Conte seu conto, Entrevistas internacionais, Eu no Orkut, Meu e-mail, Meus quinze minutos de fama, Diário, O que aprendi com Surfistinha, Ossos do ofício, Para refletir, e Sessões de Autógrafos.

\section{Considerações Finais}

Desse modo, as mediações entre a lógica dos usos e a lógica do sistema produtivo seriam instituídas por estratégias de comunicabilidade ou de interação. (cf. MARTIN-BARBERO, 2008). Estratégias que necessitam ser constantemente reafirmadas, por serem alguns dos mecanismos fundamentais de produção da crença e busca pela distinção que, na perspectiva de Bourdieu (1996), encaminham para marcar época, consistindo no ato de deter o tempo, de eternizar o estado presente e pactuar entre os agentes a continuidade, a identidade e a reprodução. 
Meios e mediações, literatura, economia e sociedade, faces de uma economia de símbolos moldada entre pressões e expressões. Oriundo do latim scorpius, Escorpião é uma das constelações mais antigas que foram identificadas e, segundo a mitologia grega, representa um animal enviado por Diana para atacar o gigante Órion. Por isso que quando a constelação de Escorpião nasce no horizonte leste, a de Órion se põe no horizonte oeste. Raquel envia o seu escorpião para atacar conceitos, posições e pré-conceitos. Só não se sabe quanto tempo durará esta constelação no universo da literatura.

\section{Referências}

AMORIM, Galeno (Org.). Retratos da leitura no Brasil. São Paulo. Imprensa Oficial do Estado de São Paulo, Instituto Pró-livro, 2008.

BAUMAN, Zygmunt. Vida Líquida. Rio de Janeiro: Jorge Zahar, 2007.

BOURDIEU, Pierre. A produção da crença: contribuição para uma economia dos bens simbólicos. São Paulo: Zouk, 2002.

BOURDIEU, Pierre. O poder simbólico. 2. ed. Rio de Janeiro: Bertrand Brasil, 1998.

BOURDIEU, Pierre. As regras da arte: gênese e estrutura do campo literário. São Paulo: Companhia das Letras, 1996.

BOURDIEU, Pierre. Questões de sociologia. Rio de Janeiro: Marco Zero, 1983.

CARDELLO, Rafael; MATTOS, Laura. Para especialista, "Surfistinha é Paulo Coelho do sexo". Folha Online, 3 set. 2006. Disponível em: www1.folha.uol.com.br/ilustrada/ ult9ou64009.shtml. Acesso em: 10 jan. 2018.

CARDOSO, Marília Rothier. Retorno à biografia. In: OLINTO, Heidrun Krieger; SCHOLLHAMMER, Karl Erik (Orgs.). Literatura e mídia. Rio de Janeiro: PUC-Rio; São Paulo: Loyola, 2002.

DUQUE, Alejandra. A agenda de Virgínia: uma prostituta de luxo revela sua vida dupla. São Paulo: Planeta do Brasil, 2006.

FARIAS, Edson. Economia e cultura no circuito das festas populares brasileiras. Sociedade e Estado, Brasília, v. 20, n. 3, set./dez., 2005. https://doi.org/10.1590/ $\underline{\text { S0102-69922005000300007 }}$

FOUCAULT, Michel. A ordem do discurso. 15. ed. São Paulo: Loyola, 2007.

FOUCAULT, Michel. História da sexualidade I: a vontade de saber. 17. ed. São Paulo: Graal, 2006. 
HERSCHMANN, Micael; PEREIRA, Carlos Alberto Messeder. O boom da biografia e do biográfico na cultura contemporânea. In: OLINTO, Heidrun Krieger; SCHOLLHAMMER, Karl Erik (Orgs.). Literatura e mídia. Rio de Janeiro: PUC-Rio; São Paulo: Loyola, 2002.

ROHTER, Larry. Aquela que controla seu corpo pode irritar seus compatriotas. Blog do The New York Times, São Paulo, 27 abr. 2006.

LAJOLO, Marisa; ZILBERMAN, Regina. O preço da leitura: leis e números por detrás das letras. São Paulo: Ática, 2001.

LEITÃO, Débora Krischke; MACHADO, Rosana Pinheiro. O luxo do povo e o povo do luxo: consumo e valor em diferentes esferas sociais. In: LEITÃO, Débora; NOGUEIRA, Diana; MACHADO, Rosana (Orgs.). Antropologia \& Consumo: diálogos entre Brasil e Argentina. Porto Alegre: AGE, 2006.

LEITE JÚNIOR, Jorge. Das maravilhas e prodígios sexuais: a pornografia 'bizarra' como entretenimento. São Paulo: Annablume, 2006.

MARTIN-BARBERO, Jesús. Dos meios às mediações: comunicação, cultura e hegemonia. 5. ed. Rio de Janeiro: UFRJ, 2008.

MATTOS, Laura. Ex-prostituta Bruna Surfistinha deve lançar filme sobre sua vida. Folha Online, 8 abr. 2007. Disponível em: www1.folha.uol.com.br/ilustrada/ult9ou70086. shtml. Acesso em: 10 jan. 2018.

MATTOS, Laura. Diários de ex-prostitutas viram fenômenos de venda. Folha Online, 3 set. 2006. Disponível em: www1.folha.uol.com.br/ilustrada/ult90u64007.shtml. Acesso em: 10 jan. 2018.

MORAES, Samantha. Depois do Escorpião: uma história de amor, sexo e traição. São Paulo: Seoman, 2006.

OLIVEIRA, Vanessa de. 0 diário de Marise: a vida real de uma garota de programa. São Paulo: Matrix, 2006.

PACHECO, Raquel. Na cama com Bruna Surfistinha: receitas de prazer e sedução. São Paulo: Panda Books, 2007.

PACHECO, Raquel. O que aprendi com Bruna Surfistinha: lições de uma vida nada fácil. São Paulo: Panda Books, 2006.

PERRONE-MOISÉS, Leyla. Altas literaturas: escolha e valor na obra crítica de escritores modernos. São Paulo: Companhia das Letras, 1998.

RUBINSTEINN, Gabriel. Um blog, uma história e o sucesso literário. Oba, Oba, 2006. Disponível em: http://www.obaoba.com.br/noticias/revistao/231/comportamento. asp. Acesso em: 10 jan. 2018. 
SURFISTINHA, Bruna. 0 doce veneno do escorpião: o diário de uma garota de programa. São Paulo: Panda Books, 2005.

TELES, Gilberto Mendonça. O mercado do livro universitário. In: OLINTO, Heidrun Krieger; SCHOLLHAMMER, Karl Erik (Orgs.). Literatura e mídia. Rio de Janeiro: PUCRio; São Paulo: Loyola, 2002.

TELLES, Sérgio. Algumas ideias sobre os dois livros de Bruna Surfistinha. Mente \& Corpo, n. 169, fev. 2007.

\section{Dados do autor}

\section{Clovis Carvalho Britto: clovisbritto5@hotmail.com}

Pós-Doutor em Estudos Culturais pela Universidade Federal do Rio de Janeiro. Doutor em Sociologia pela Universidade de Brasília. Professor da Faculdade de Ciência da Informação da Universidade de Brasília - UnB.

Endereço do autor: Universidade de Brasília, Faculdade de Ciência da Informação. Campus Universitário Darcy Ribeiro. Prédio da Biblioteca Central - Entrada Leste, Asa Norte, 70.910-900, Brasília (DF), Brasil 